\title{
RANCANG BANGUN RANGKA MESIN PLANER KAYU OTOMATIS DENGAN PENGGERAK MOTOR LISTRIK
}

\author{
Danang Abdul Majid \\ Fakultas Teknik, Program Studi Teknik Mesin \\ Universitas Muria Kudus \\ Email: danangabdulmajid@outlook.com \\ Rochmad Winarso \\ Fakultas Teknik, Program Studi Teknik Mesin \\ Universitas Muria Kudus \\ Email : rochmad.winarso@umk.ac.id \\ Qomaruddin \\ Fakultas Teknik, Program Studi Teknik Mesin \\ Universitas Muria Kudus \\ Email : qomaruddin@umk.ac.id
}

\begin{abstract}
ABSTRAK
Kerajinan dan Produk dari bahan kayu menjadi produk yang banyak diminati masyarakat. Pengolahan kayu memerlukan adanya proses dengan menggunakan mesin planer untuk meratakan permukaan kayu. Merancang mesin planer yang menggunakan penggerak otomatis sesuai perkembangan technology. Rangka mesin planer merupakan komponen utama dari mesin planer. Metode yang digunakan meliputi studi literatur, proses perancangan, proses manufaktur dan simulasi menggunakan software inventor 2016. Hasil penelitian adalah telah dibuat rangka mesin planer otomatis dan memiliki dimensi benda kerja maksimal $20 \mathrm{~cm} \times 10 \mathrm{~cm} \times 80 \mathrm{~cm}$. Hasil penelitian menunjukkan bahwa tegangan von mises stress yang terjadi mencapai $0.449001 \mathrm{mpa}$ dari hasil simulasi sedangkan pada perhitungan manual von mises stress mencapai 0,4504 mpa displacement yang dihasilkan simulasi $0,0003827 \mathrm{mpa}$ dan perhitungan manual 0,00396 mpa dengan galat \%eror von mises stress $0,3 \%$ dan displacement $3,6 \%$
\end{abstract}

Kata kunci: planer, kayu,rangka,simulation autodesk inventor,von mises stress,displacement

\begin{abstract}
Handicrafts and products made from wood are products that are in great demand by the community. Wood processing is needed by using a planer machine to flatten the wood surface. The planner machine design is using automatic drives corresponden with technology develompment. Planer machine frames are components the main planer machine. The method used includes the study of literature, design process, manufacturing process and simulation using Inventor 2016 software. The results of research was made automatic planer machine frames and have a workpiece dimension of maximum $20 \mathrm{~cm} \times 10 \mathrm{~cm} x 80 \mathrm{~cm}$, the results of research was show that von mises stress which happened to reach 0.449001 mpa from the simulation results whereas in the manual calculation of von mises stress reached 0.4504 mpa displacement generated simulation 0,0003827 mpa and manual calculation 0.00396 mpa with\% error error von mises stress $0.3 \%$ and displacement $3.6 \%$
\end{abstract}

Keywords: planer, wood, framework, autodesk simulation inventor, von mises stress, displacement 


\section{PENDAHULUAN}

Manusia mempunyai kebutuhan yang semakin kompleks, maka diperlukan teknologi sebagai jawaban untuk mempermudah dalam memenuhi kebutuhan tersebut. Penciptaan alat adalah salah satu perwujudan dalam perkembangan teknologi tersebut.

Kerajinan kayu dan produk yang dihasilkan dewasa ini menjadi salah satu kebutuhan manusia yang penting, salah satu kerajinan dari bahan baku kayu adalah meubel, sangkar burung dan produk olahan kayu lainnya, pada saat ini mengalami banyaknya permintaan akan produksi yang kurang diimbangi dengan ketepatan penyelesaian akan order, dikarenakan SDM dan Teknologi[1]

Dahulu seorang tukang menyerut kayu dengan menggunakan serutan manual, sekarang sudah menggunakan serutan elektrik yang disebut "planer". Alat ini masih menggunakan engkol manual untuk menaikkan meja mesin planer, maka dari itu diperlukan inovasi teknologi yaitu dengan merancang mesin planer yang mnggunakan penggerak otomatis dengan system kontrol.

Mesin Planer mempunyai Komponen yang memiliki fungsinya masing-masing. Jika salah satu fungsi dari komponen tersebut tidak terpenuhi maka akan berakibat terhadap hasil kinerja dari mesin planer. Dari beberapa komponen tersebut, rangka mesin merupakan komponen yang memiliki fungsi terpenting. Hal itu dikarenakan rangka merupakan sebuah komponen utama yang berfungsi sebagai penopang dari seluruh komponen pendukung mesin planer lainnya. [2]

Rangka merupakan komponen utama dari mesin planer yang berfungsi sebagai penopang, maka rangka haruslah memiliki kriteria yang harus dimiliki oleh sebuah rangka yang baik. Rangka yang baik merupakan rangka yang bisa menahan beban dari komponen-komponen yang menimpanya, rangka yang bisa menahan getaran yang timbul akibat proses kerja mesin, rangka yang memiliki kesejajaran antara kaki-kaki rangka dan penyangga-penyangga komponen mesin.[3] Berdasarkan uraian masalah pada latar belakang tersebut akan melakukan beberapa konsep desain rangka dari perancangan mesin planer kayu dan gambar rangkaian kerangka secara keseluruhan sehingga terbentuk sebuah Mesin planer otomatis.

\section{METODOLOGI PENELITIAN}

Tahap proses perancangan rangka Mesin Planer Kayu Otomatis dengan penggerak motor listrik dapat dilihat pada gambar 1 dibawah ini 


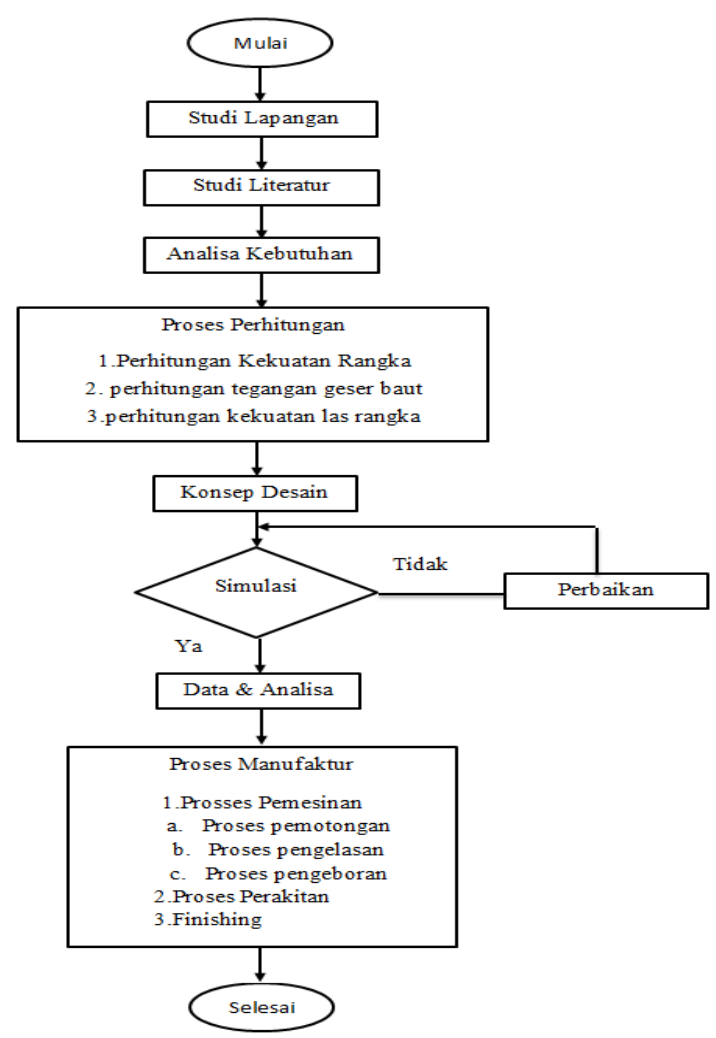

\section{Gambar 1. Diagram alir rancang bangun}

Studi literatur merupakan satu cara yang dipakai data untuk menghimpun data-data yang berhubungan dengan rangka mesin planer dalam suatu penelitian. Konsep design pada rangka mesin planer dapat dilihat dari analisa kebutuhan, dimensi serta material yang digunakan untuk rangka mesin planer. Perhitungan rangka mesin planer meliputi perhitungan tegangan pada rangka, tegangan geser baut dan perhitungan kekuatan las rangka. Simulasi design bertujuan untuk menentukan hasil output simulasi adalah von mises stress, displacement,dan safety factor. Data dan analisa memberikan informasi mengenai hasil dari simulasi. Proses Manufaktur meliputi Proses pemotongan, proses pengelasan, proses pengeboran dan proses perakitan. Untuk gambar rangka mesin Planer dapat dilihat pada gambar 2 di bawah ini 


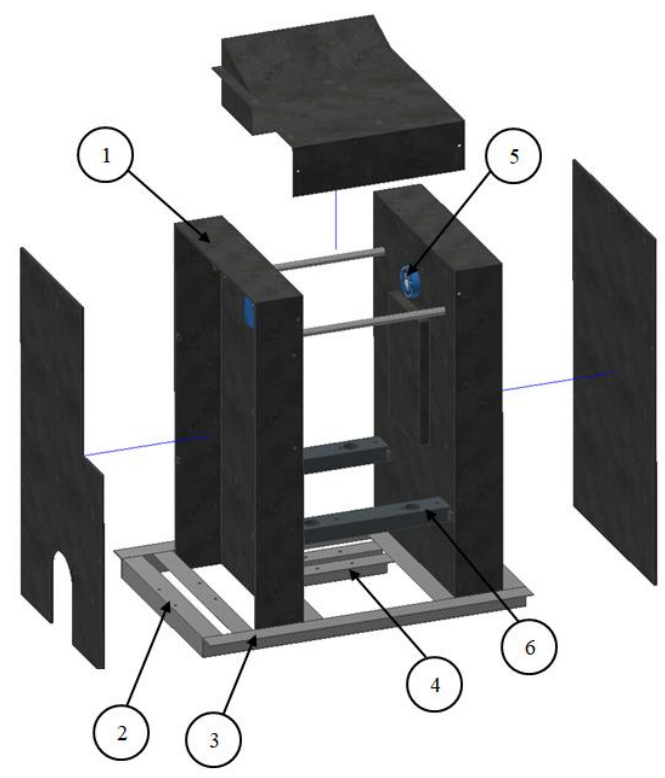

Keterangan :

Gambar 2. Rangka Mesin Planer

1. Rangka atas

2. Dudukan motor listrik

3. Rangka bawah

4. Dudukan motor stepper

5. Dudukan cutter block

6. Dudukan meja

Sistem kerja dari mesin planer kayu adalah sebagai beikut :

1. Menginput program pada keypad sistem kontrol sesuai dengan tebal benda kerja yang akan diproses dengan maksimal dimensi benda kerja $80 \mathrm{~cm}$ x $20 \mathrm{~cm}$ x $10 \mathrm{~cm}$

2. Menghidupkan conveyor dengan menyalakan saklar.

3. Meletakkan benda kerja yang akan diproses ke conveyor bagian depan

4. Benda kerja akan terbawa conveyor ke cutter block untuk proses penyerutan

5. Setelah proses penyerutan benda kerja oleh cutter block selesai, material akan tercurahkan pada ujung conveyor

\section{HASIL DAN PEMBAHASAN}

Pada Proses perencanaan rangka mesin planer ini meliputi proses desain, perhitungan rangka, perhitungan pembuatan dan proses pengujian.

\subsection{Proses Perancangan}

Perhitungan rangka mesin planer kayu otomatis dibutuhkan proses perhitungan untuk mempermudah proses pembuatan atau perencanaan. Maka diperlukan proses perhitungan beban diatas rangka.

Perencanaan ukuran dimensi rangka mesin planer merupakan hal yang penting untuk menentukan seberapa besar rangka yang digunakan berdasarkan pada komponen lainnya. Untuk dimensi rangka mesin planer dapar dilihat pada gambar 3 dibawah ini: 

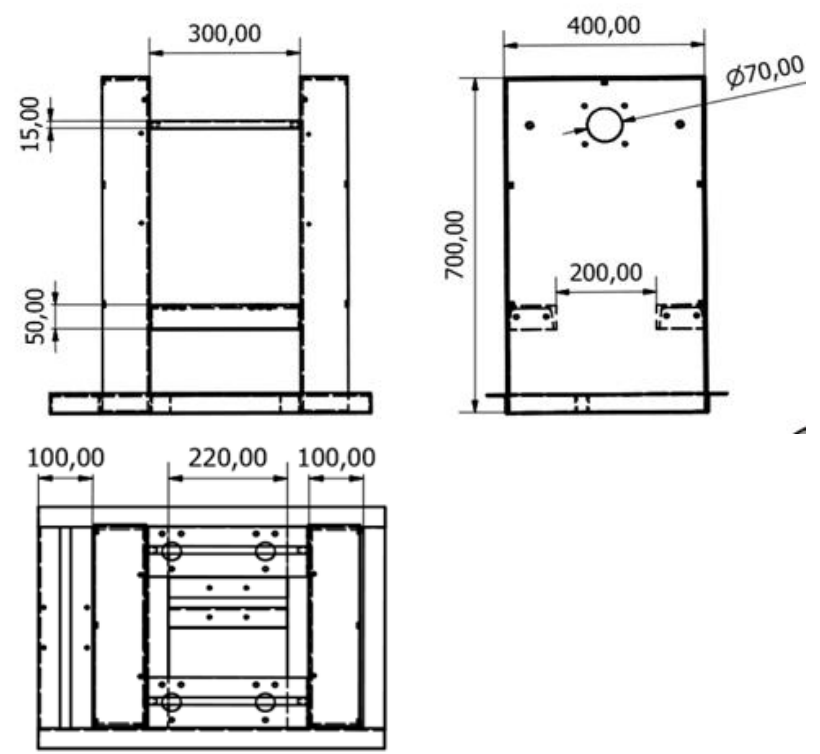

\section{Gambar 3 dimensi rangka}

Untuk melakukan perhitungan rangka perlu dilakukan perhitungan massa beban di atas rangka. Volume dan massa meja planer dihitung dengan menggunakan persamaan berikut :

Volume meja :

$$
\mathrm{v}=\mathrm{p} \times 1 \times \mathrm{t}
$$

Massa meja:

$$
m=\rho . v
$$

Volume dan massa roller conveyor dihitung dengan menggunakan persamaan berikut :

Volume roller :

$$
v=\pi \cdot r^{2} \cdot t
$$

Massa roller:

$$
m=\rho . v
$$

Volume dan massa belt planer dihitung dengan menggunakan persamaan berikut :

Volume belt:

$$
v=l b \cdot p b \cdot t b
$$

\section{Massa belt:}

$$
m b=\rho b . v b
$$

Volume dan massa ulir penyangga meja dihitung dengan menggunakan persamaan berikut : 
Volume ulir $\quad v=\frac{\pi}{4} \cdot D^{2} \cdot t$

Massa ulir $\quad m=V . \rho$

Volume dan massa benda kerja dihitung dengan menggunakan persamaan berikut :

Volume benda kerja:

$$
\mathrm{v}=\mathrm{p} \times 1 \times \mathrm{t}
$$

Massa benda :

$$
m=\rho . v
$$

Volume dan massa cutter block dihitung dengan menggunakan persamaan berikut :

Volume cutter block

$v=\pi x r^{2} x t$

Massa cutter block

$m=\rho . v$

Pada perhitungan massa diatas rangka dapat dilihat pada tabel 1 dibawah ini :

Tabel 1 hasil perhitungan massa diatas rangka

\begin{tabular}{lccc}
\hline \multicolumn{1}{c}{ Perhitungan } & QTY & Bahan & Hasil \\
\hline Meja planer & 1 & St 37 & $12,7 \mathrm{~kg}$ \\
Roller conveyor & 2 & St 37 & $0,89 \mathrm{~kg}$ \\
Belt conveyor & 1 & Rought top & $1,9 \mathrm{~kg}$ \\
Ulir penyangga meja & 4 & St 60 & $3,9 \mathrm{~kg}$ \\
Benda Kerja & 1 & jati & $11,2 \mathrm{~kg}$ \\
Cutter block & 1 & St 60 & $6,4 \mathrm{~kg}$ \\
Motor stepper & 1 & - & $3 \mathrm{~kg}$ \\
\hline
\end{tabular}

\subsection{Simulasi design}

Pengujian pada rangka mesin planer ini dilakukan dengan analisa beban statis pada rangka mesin planer dengan menggunakan software inventor 2016. Dengan input $183 \mathrm{~N}$ pada pada rangka tumpuan meja depan dan 154,5 N pada rangka tumpuan meja belakang. Pada hasil simulasi design ini maka diperoleh data pada gambar 4 sebagai berikut : 
Von Mises Stress

Type: Von Mises Stress

Unit: $\mathrm{MPa}$

1/27/2019, 9:23:30 PM

$0.4487 \mathrm{Max}$

0.359

0.2692

0.1795

0.0897

$0 \mathrm{Min}$

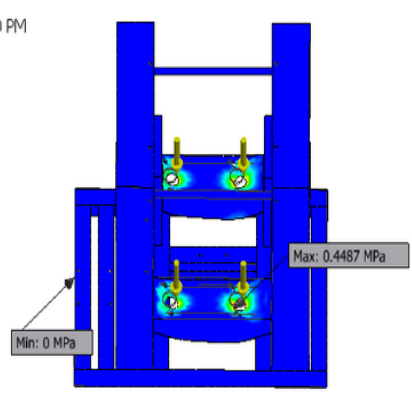

Type: X Displacement

Unit: $\mathrm{mm}$

1/27/2019, 9:23:34 PM

5.692e-005 Max

$4.791 \mathrm{e}-005$

$3.593 \mathrm{e}-005$

$2.396 \mathrm{e}-005$

$1.198 \mathrm{e}-005$

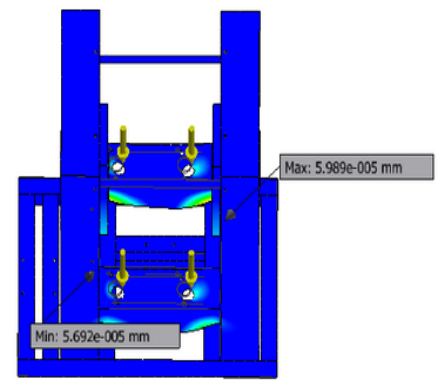

\section{Safety Factor}
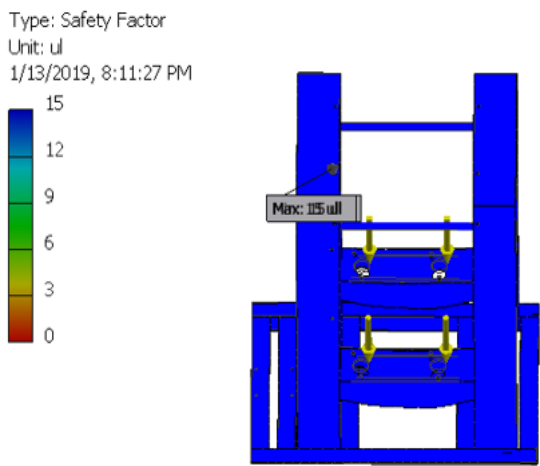

Gambar 4. Hasil Simulasi

Parameter simulasi design dapat dilihat pada tabel 2 berikut :

Tabel 2 parameter yang digunakan dalam simulasi

\begin{tabular}{lc}
\hline \multicolumn{1}{c}{ Properties } & Value \\
\hline Mass Density & $7.85 \mathrm{~g} / \mathrm{cm}^{3}$ \\
Yield Strength & $207 \mathrm{MPa}$ \\
Ultimate Tensile Strength & $345 \mathrm{MPa}$ \\
Young's Modulus & $220 \mathrm{GPa}$ \\
Poisson's Ratio & $0.275 \mathrm{ul}$ \\
Shear Modulus & $86.2745 \mathrm{GPa}$ \\
\hline
\end{tabular}

\subsection{Perhitungan Rangka}

Proses perhitungan pada rangka mesin planer didasarakan pada rumus berikut : Tegangan 


$$
\sigma=\frac{M \cdot c}{i}
$$

Dengan M adalah momen bending, c adalah titik berat dan I adalah inersia penampang Safety factor

$$
s f=\frac{\text { oijin }}{\text { orangka }}
$$

Dengan $s f$ adalah safety factor, $\sigma i j i n$ adalah tegangan ijin dan $\sigma r a n g k a$ adalah tegangan pada rangka

Tegangan geser[4]

$$
\tau_{g}=\frac{V}{A}
$$

Dengan adalah tegangan geser, $\mathrm{V}$ adalah gaya pada rangka dan $\mathrm{A}$ adalah luas permukaan Defleksi

$$
\delta=\frac{P . l}{A . E}
$$

Dengan adalah defleksi, $\mathrm{P}$ beban pada rangka, I adalah inersia, A adalah luas penampang dan $\mathrm{E}$ adalah modulus Elastisitas

Von mises stress maksimum[5] dapat dihitung dengan persamaan 17 :

$\sigma \max =\frac{\sigma_{x}+\sigma_{y}}{2}+\sqrt{\left(\frac{\sigma_{x}+\sigma_{y}}{2}\right)^{2}+\left(\tau_{x y}\right)^{2}}$

Von mises stress minimum

$\sigma \min =\frac{\sigma_{x}+\sigma_{y}}{2}-\sqrt{\left(\frac{\sigma_{x}+\sigma_{y}}{2}\right)^{2}+\left(\tau_{x y}\right)^{2}}$

Tegangan tarik baut

$$
F t=\frac{\pi}{4} d_{i}^{2} \cdot \sigma_{t} \cdot n
$$

Kekuatan Sambungan las

$$
\begin{aligned}
& \sigma b=\frac{F}{A} \\
& \sigma_{t}=\sigma_{b} x \sigma_{t}
\end{aligned}
$$

$\sigma_{\mathrm{tijin}} \geq \sigma_{\mathrm{t}}$ artinya tegangan yang diijinkan $\left(\sigma_{\mathrm{t}} \mathrm{jin}\right)$ lebih besar dibandingkan dengan tegangan yang terjadi pada rangka $\left(\sigma_{t}\right)$, maka rangka dinyatakan aman.[6] Hasil perhitungan dapat dilihat pada tabel 3 berikut. 
Tabel 3. Hasil perhitungan rangka

\begin{tabular}{lc}
\hline$\quad$ Perhitungan & Hasil \\
Tegangan & $12,54 \mathrm{~N} / \mathrm{mm}$ \\
Safety factor & 19,13 \\
Tegangan geser & $0,0061 \mathrm{~N}$ \\
Defleksi & $0,000842 \mathrm{~mm}$ \\
Von mises maximum & $0,569 \mathrm{mpa}$ \\
Von mises minimum & $0,001 \mathrm{mpa}$ \\
\hline
\end{tabular}

\subsection{Proses pengujian}

Pada pengujian ini dilakukan pengujian software simulasi, pengujian stress analysis, pengujian kerangka mesin planer bertujuan untuk mengetahui kekuatan dari dari kerangka mesin planer sehingga akan didapatkan hasil kekuatan yang sesuai dengan perencanaan yang diharapkan

Pengujian pada kerangka mesin planer ini dilakukan dengan analisa beban statis pada kerangka ini menggunakan software inventor 2016 sehingga diperoleh output von mises stress, displacement dan safety factor[6]. Pada hasil simulasi dapat dilihat pada tabel 4 berikut ini.

Tabel 4. Hasil Simulasi

\begin{tabular}{lll}
\hline \multicolumn{1}{c}{ Name } & \multicolumn{1}{c}{ Minimum } & \multicolumn{1}{c}{ Maximum } \\
\hline Mass & $55,6741 \mathrm{~kg}$ & - \\
Volume & $7092240 \mathrm{~mm}^{3}$ & - \\
Von Mises Stress & $0,000000894193 \mathrm{MPa}$ & $0,449001 \mathrm{Mpa}$ \\
Displacement & $0 \mathrm{~mm}$ & $0,000382748 \mathrm{~mm}$ \\
Safety factor & $15 \mathrm{ul}$ & $15 \mathrm{ul}$ \\
\hline
\end{tabular}

Berdasarkan tabel pengujian software didapatkan hasil von mises stress maximum 0,449001 Mpa sehingga rangka dinyatakan aman karena von mises stress lebih kecil dibandingkan dengan material bahan yield strenght $207 \mathrm{Mpa}$

Perhitungan galat presentase pada kerangka mesin[7] planer meliputi von mises stress dan Displacement adalah sebagai berikut :

$$
\% \text { eror }=\frac{\text { perhitungan teoritis }- \text { simulasi } \text { software }}{\text { simulasi } \text { software }} .100
$$

Pada hasil perhitungal galat dapat dilihat pada tabel 5 berikut :

Tabel 5

\begin{tabular}{ll}
\hline \multicolumn{1}{c}{ Perhitungan } & Hasil \\
\hline Von Misess Stress & $0,3 \%$ \\
Displacement & $3,6 \%$ \\
\hline
\end{tabular}

\section{KESIMPULAN}

Dari rancang bangun rangka mesin planer otomatis dengan penggerak motor listrik dapat disimpulkan sebagai berikut :

1. Design rangka mesin menggunakan plat st 37 dengan tinggi $700 \mathrm{~mm}$, lebar $400 \mathrm{~mm}$ dan tebal 4 $\mathrm{mm}$, tumpuan meja menggunakan kanal $\mathrm{U}$ dan rangka bawah menggunakan Kanal L.

2. Pada proses pengujian dengan menggunakan software inventor 2016 rangka mengalami von mises stress min: $0 \mathrm{MPa}$ dan $\max : 0.449001 \mathrm{Mpa}$, displacement $\mathrm{min}$ : $0 \mathrm{~mm}$ dan nilai $\max$ : 
$0.000382748 \mathrm{~mm}$, dan nilai $\mathrm{SF} \geq 1$ sehingga rangka dinyatakan aman dan masih memenuhi galat yang ditentukan.

3. Pada proses pembuatan rangka mesin planer meliputi proses pembuatan rangka atas,rangka tumpuan meja dan rangka bawah dan menggunakan motor listrik single phase AC motor type JY1A-4 1/2 HP $1450 \mathrm{rpm} 110 / 220 \mathrm{v} 4 / 4.2 \mathrm{~A} 50 \mathrm{~Hz}$

\section{DAFTAR PUSTAKA}

[1] Safari yoso Utomo, "perancangan rangka mesin hot press particle board dengan penggerak hidroliss untuk ukuran volume papan $122 \mathrm{~cm}$ x $22 \mathrm{~cm}$ x 1.8cm," 2013.

[2] April yanto Wibowo, "proses pembuatan rangka pada mesin roll pelat penggerak elektrik," universitas negeri yogyakarta, 2011.

[3] A. Hidayat and S. Bambang, "perancangan mesin perajang daun tembakau," p. 8, 2013.

[4] Sularso and K. Suga, elemen mesin. jakarta: pradnya paramita, 2004.

[5] S. Kuntoro and M. Kabib, "Analisa Kekuatan Dies Frame Link Pada Mesin Roll Pipa 2 In Penggerak Hidrolik Dengan Metode Elemen Hingga," Jurnal Simetris vol. 9, no. 2, pp. 941-946, 2018.

[6] B. Setyono, Mrihrenaningtyas, and A. Hamid, "Perancangan Dan Analisis Kekuatan Frame Sepeda Hibrid ' Trisona' Menggunakan Software Autodesk Inventor," IPTEK, vol. 20, pp. 37-46, 2016.

[7] Muhamad rizal Azhari, "Perancangan mesin pemarut dan Pemeras umbi ganyong (canna edulis ker) dengan kapasitas 200 kg/jam," universitas muria kudus, 2018. 